\title{
The Relationship Between Volunteers' Attitude Towards Palliative Care and Spiritual Care Competence: a Cross-sectional Study
}

\section{Jingrong Wang}

Shanghai University of Traditional Chinese Medicine

\section{Yifan Xu}

Shanghai University of Traditional Chinese Medicine

\section{Tiantian Li}

Anhui Medical University

\section{Xing Jue}

Shanghai Jue Qun Cultural \& Educational Foundation

\section{Zhiqun Shu}

Shanghai Ninth People 's Hospital, Shanghai Jiaotong University School of Medicine

Jue Hui

Shanghai Jue Qun Cultural \& Educational Foundation

\section{Xueying Li}

Shanghai University of Traditional Chinese Medicine

Limei Jing ( $\square$ limei_jing@163.com )

Shanghai University of Traditional Chinese Medicine

\section{Research Article}

Keywords: spiritual care, competence, volunteer, palliative care

Posted Date: February 10th, 2022

DOI: https://doi.org/10.21203/rs.3.rs-1298606/v1

License: (c) (1) This work is licensed under a Creative Commons Attribution 4.0 International License. Read Full License 


\section{Abstract}

Background: With the rising burden of palliative care and limited health care resource, volunteers are an integral resource in palliative care. However, the spiritual care competence and the relationship between spiritual care competence and attitude towards palliative care among volunteers has rarely been investigated. This study examined volunteers' spiritual care competence; and identified factors affecting spiritual care competence.

Methods: The correlational study was conducted with 385 volunteers in Shanghai, China. Data was collected using a structured questionnaire.

Results: Volunteers' spiritual care competence level was not high (58.50 \pm 10.92$)$. And attitude towards palliative care was significantly correlated with spiritual care competence $(r=0.49, p<0.001)$. A statistically significant correlation was found between spiritual care competence and the following variables: age, education background, marital status, religious belief, occupational status, relevant experience of practice and training.

Conclusion: A need exists to organize and design diversified education and training programs about spiritual care targeting to different kinds of volunteers to continually improve their spiritual care competence. Considering attitude towards palliative care is a significant factor of spiritual care competence, education and training programs should be developed to help volunteers establish positive attitude towards palliative care.

\section{Background}

According to the definition by World Health Organization, palliative care is an approach that improves the quality of life of patients and their families facing the problems associated with life-threatening illness through the prevention and relief of suffering by means of early identification and impeccable assessment and treatment of pain and other problems, whether physical, psychosocial or spiritual[1]. About one in five among patients in palliative care was identified as "spirituality distressed"[2]. At present, the incidence of cancer is high, and most cancer patients have spiritual issues[3]. Spirituality refers to relationships with the self and with God/a Supreme Being (i.e. the beyond dimension)[4]. Chang believed that the concept of spirituality in traditional Chinese culture exceeds the scope of religion[5]. It means that people understand the meaning of life, maintain harmonious interpersonal relationships, and transcend themselves through interactions with themselves and the environment. In face of the need to pay attention to spiritual, palliative care has moved away from the concept of symptom control toward holistic treatment. Answering the spiritual needs of patients is accepted as a basic factor in high quality palliative care.

It was estimated that around 7.5 million people needed palliative care in China[6], with only $3 \%$ of them received relative service[7]. With the growing demand for palliative care, there is a substantial gap in the availability of palliative care. So a model of palliative care, based solely on specialist providers, can not 
meet the demands[8]. It is necessary to attach importance to the role of volunteers. Volunteering in palliative care is defined as the time freely given by individuals, with no expectation of financial gain, within some form of organized structure other than the already existing social relations or familial ties, with the intention of improving the quality of life of adults and children with life-limiting conditions and those close to them (family and others)[9]. Palliative care interventions that involve volunteers have a positive impact on family satisfaction with care and may even lengthen patient survival[10]. Volunteers not only have beneficial affect on the patients, but also give family caregivers support. Specifically, the benefits for family caregivers include respite or breaks from their caregiving role, emotional support, social support, advocacy, practical assistance and spiritual support[11]. There role of being there and liaison help fill the gaps between professionals and family[12]. Volunteers provide an informal educative role in the community, both with regard to de-stigmatising hospice connotations, and in terms of promotion and reinforcing the hospice reputation locally[13]. Moreover, their contribution reduces palliative care costs by an estimated $23 \%[14]$. In view of the limited health care resource and the grim situation of aging, volunteers are expected to play a more important role in palliative care in the future[15]. Although the importance of spiritual care has been emphasized, most literature regarding spiritual care has seldom focused on the role of volunteers.

In the process of providing services, volunteers have to deal with the heavy theme of death and have to take care of patients approaching death[16]. In such a working environment, they are prone to fear and anxiety, which may lead to negative attitude towards palliative care and then reduce the quality of services, especially in the aspect of spiritual care. In order to effectively improve volunteers' spiritual care competence, it is necessary to shed light on their attitude towards palliative care. There remains researches exploring volunteers attitude towards palliative care, but the relationship between attitude towards palliative care and spiritual care competence among volunteers has rarely been investigated. Thus, this study examined the attitude towards palliative care and spiritual care competence among volunteers.

\section{Methods}

\section{Aims}

The study aimed to (1) measure the attitude towards palliative care and spiritual care competence among volunteers; (2) explore the relationship between volunteers' attitude towards palliative care and spiritual care competence; and (3) identify factors related with volunteers' spiritual care competence.

\section{Study design}

A cross-sectional descriptive study using a form of general characteristics and two scales of spiritual care competence and attitude towards palliative care among volunteers. Before the formal investigation, we recruited 41 volunteers participating in the pre-investigation to examine the reliability of the scales. The Cronbach's $\otimes$ for spiritual care competence scale was 0.916 , and the KMO was 0.931 . The Cronbach' $\mathrm{s} \otimes$ for spiritual care competence scale was 0.768 , and the KMO was 0.624 . 


\section{Sample and setting}

For multivariable analyses, rules of numb are often adopted that the sample size should be 5,10 , or 20 times the number of variables[17].There were 9 variables in this study so the sample size was supposed to be 180. Convenience sampling was used to recruit participants from typical voluntary organizations in Shanghai, China in January 2019. The inclusion criteria were: (1) volunteers involved in palliative care or having the will to participate in palliative care; and (3) able to understand the study purpose and provide informed consent. 385 volunteers participated in the study.

\section{General characteristics}

We collected participants' general characteristics including sex, age, education background, marital status, religious belief, occupational status, whether they had participated in palliative care, whether they had been exposed to knowledge about palliative care, whether training was received for palliative care.

\section{Spiritual care competence}

The measurement scales for spiritual care competence is limited. Van Leeuwen et al. [18]developed the Spiritual Care Competence Scale based on the framework of spiritual care competence. The questionnaire consists of six core domains: assessment and implementation of spiritual care, professionalization and improving the quality of spiritual care, personal support and patient counseling, referral to professionals, attitude towards the patient's spirituality and communication. It has been translated, revised and applied by researchers in China[19-21]. However, it is only applicable to nurses, not to volunteers investigated in this study. Chen et al.[22,23] developed the spiritual care competence scale based on the scale mentioned above. It is applicable to volunteers, which consists of three core domains: basic knowledge, attitude and professional skills. For a better understanding of Chinese population, the scale was revised based on the language environment in mainland China. The scale consists of 18 items and employs a five-point Likert scale ( $1=$ strongly disagree to $5=$ strongly agree). Total scores range from 18 to 90 , with higher scores indicating higher competence levels.

\section{Attitude towards palliative care}

The measurement scale for attitude towards palliative care was developed based on the attitudes toward care of the dying scale developed by Frommelt et al.[24] and the attitude questionnaire developed by Liu et al.[25]. The scale contains 20 items, consisting of four core domains (facing advanced patients, improving the quality of life, preparing for death and obstacles to palliative care). The scale employs a five-point Likert scale ( $1=$ strongly disagree to $5=$ strongly agree). Total scores range from 20 to 100 , with higher scores indicating more positive attitude.

\section{Statistical analysis}

Data were analyzed with IBM SPSS 23.0. Continuous variables were presented as means and standard deviation. Categorical variables were presented as numbers and percent. Spearman correlation was 
conducted to detect the relationship between spiritual care competence and attitude towards palliative care. Multiple linear regression analysis, ANOVO and t test were used to identify the factors affecting the volunteers' spiritual care competence. A p value of $<0.05$ was considered statistically significant.

\section{Results}

\section{Participant characteristics}

Participants characteristics are shown in Table 1. Of 385 participants, $77.7 \%(n=299)$ were women, and the mean age was $29.04 \pm 12.82$. 58.2\% (224) were non-religious, and $70.4 \%$ (271) were unmarried. 211 participants (54.8\%) were college students. 265 participants (68.8\%) did not have experience in caring for terminally ill patients or relatives. 243 participants $(63.1 \%)$ had not been exposed to knowledge about palliative care. 327 participants $(84.9 \%)$ had not received any training related to palliative care.

Table 1 Participant Characteristics ( $\mathrm{N}=385)$ 


\begin{tabular}{|c|c|c|c|}
\hline \multicolumn{2}{|l|}{ Characteristics } & \multirow{2}{*}{$\begin{array}{l}n \\
86\end{array}$} & \multirow{2}{*}{$\begin{array}{l}\% \\
22.3\end{array}$} \\
\hline Sex & Male & & \\
\hline & Female & 299 & 77.7 \\
\hline \multirow[t]{3}{*}{ Age } & $\leq 30$ & 247 & 64.2 \\
\hline & $30-50$ & 79 & 20.5 \\
\hline & $\varangle 50$ & 59 & 15.3 \\
\hline \multirow[t]{3}{*}{ Education background } & $\leq$ Associate & 61 & 15.8 \\
\hline & Bachelor & 278 & 72.2 \\
\hline & $\geq$ Master & 46 & 12.0 \\
\hline \multirow[t]{3}{*}{ Marital status } & Unmarried & 271 & 70.4 \\
\hline & Married & 89 & 23.1 \\
\hline & Other & 25 & 6.5 \\
\hline \multirow[t]{2}{*}{ Religious belief } & Yes & 161 & 41.8 \\
\hline & No & 224 & 58.2 \\
\hline \multirow[t]{2}{*}{ occupational status } & College student & 211 & 54.8 \\
\hline & Social worker & 174 & 45.2 \\
\hline \multirow[t]{2}{*}{ Experience of caring for dying patients/relatives } & Yes & 120 & 31.2 \\
\hline & No & 265 & 68.8 \\
\hline \multirow[t]{2}{*}{ Exposed to knowledge about palliative care } & Yes & 142 & 36.9 \\
\hline & No & 243 & 63.1 \\
\hline \multirow[t]{2}{*}{ Received training on palliative care } & Yes & 58 & 15.1 \\
\hline & No & 327 & 84.9 \\
\hline
\end{tabular}

\section{Spiritual care competence}

Table 2 shows participants' spiritual care level. The total score was $58.50 \pm 10.92$. It was found that social volunteers' spiritual care competence $(60.28 \pm 11.34)$ was significantly higher than that of college students (57.04 \pm 10.36$)$. The significant difference was found from the dimension of attitude, but not basic knowledge and professional skills.

Table 2 Levels of spiritual care competence 


\begin{tabular}{|lllll|}
\hline Dimension & College students volunteers & Social volunteers & $\mathrm{Z} / \mathrm{t}$ & $\mathrm{p}$ \\
\hline basic knowledge & $7.37 \pm 2.28$ & $7.43 \pm 2.77$ & -.171 & 0.864 \\
\hline attitude & $24.37 \pm 5.02$ & $26.51 \pm 4.79$ & -3.993 & 0.000 \\
\hline professional skills & $25.30 \pm 4.97$ & $26.34 \pm 5.32$ & -1.520 & 0.128 \\
\hline Total & $57.04 \pm 10.36$ & $60.28 \pm 11.34$ & -2.920 & 0.004 \\
\hline
\end{tabular}

\section{Attitude towards palliative care}

Table 3 shows volunteers' attitude towards palliative care. The total attitude score was $74.54 \pm 8.58$ (range: $56-100)$. It was found that social volunteers' attitude $(76.47 \pm 8.44)$ was significantly higher than that of college students $(72.95 \pm 8.39)$. The significant difference was found from the aspects of improving the quality of life, preparing for death and obstacles to palliative care, but not facing advance patients.

Table 3 Levels of attitude towards palliative care

\begin{tabular}{|lllll|}
\hline Dimension & College students volunteers & Social volunteers & $Z$ & $p$ \\
\hline facing advanced patients & $15.55 \pm 3.77$ & $16.12 \pm 3.63$ & -1.636 & 0.102 \\
\hline improving the quality of life & $19.89 \pm 3.15$ & $20.95 \pm 2.86$ & -3.878 & 0.000 \\
\hline preparing for death & $20.10 \pm 3.24$ & $20.82 \pm 2.78$ & -2.388 & 0.017 \\
\hline obstacles to palliative care & $17.41 \pm 3.51$ & $18.58 \pm 3.29$ & -3.608 & 0.000 \\
\hline Total & $72.95 \pm 8.39$ & $76.47 \pm 8.44$ & -4.282 & 0.000 \\
\hline
\end{tabular}

\section{Relationship between spiritual care competence and attitude towards palliative care}

A significant correlation was found between spiritual care competence and attitude towards palliative care among volunteers $(r=0.494, p=0.000)$, indicating that spiritual care competence is is positively correlated to the attitude towards palliative care.

\section{Factors affecting volunteers' spiritual care competence}

Table 4 shows the results of univariate analysis and Table 5 shows the results of multiple linear regression analysis. According to the results of univariate analysis, age, education background, marital status, religious belief, occupational status, relevant experience of practice and training were significantly associated with volunteers' spiritual care competence. The multiple linear regression model fit the data 
well $(\mathrm{F}=5.427, \mathrm{p}=.000)$. Relevant experience of practice and training, being exposed to knowledge about palliative care were factors associated with volunteers' spiritual care competence, which is consistent with the result of univariate analysis.

Table 4 Results of univariate analysis

\begin{tabular}{|c|c|c|c|c|}
\hline Item & & Score & $\mathrm{F} / \mathrm{t}$ & $\mathrm{P}$ \\
\hline \multirow[t]{2}{*}{ Sex } & Male & $57.28 \pm 10.35$ & \multirow[t]{2}{*}{-1.181} & \multirow[t]{2}{*}{0.238} \\
\hline & Female & $58.86 \pm 11.07$ & & \\
\hline \multirow[t]{3}{*}{ Age } & $\leq 30$ & $57.17 \pm 10.56$ & \multirow[t]{3}{*}{7.030} & \multirow[t]{3}{*}{0.001} \\
\hline & $30-50$ & $59.44 \pm 11.82$ & & \\
\hline & $\otimes 50$ & $62.85 \pm 10.00$ & & \\
\hline \multirow[t]{3}{*}{ Education background } & $\leq$ Associate & $60.82 \pm 12.19$ & \multirow[t]{3}{*}{4.285} & \multirow[t]{3}{*}{0.014} \\
\hline & Bachelor & $57.51 \pm 10.50$ & & \\
\hline & $\geq$ Master & $61.46 \pm 10.89$ & & \\
\hline \multirow[t]{3}{*}{ Marital status } & Unmarried & $57.45 \pm 10.47$ & \multirow[t]{3}{*}{4.755} & \multirow[t]{3}{*}{0.009} \\
\hline & Married & $60.55 \pm 10.78$ & & \\
\hline & Other & $62.68 \pm 14.19$ & & \\
\hline \multirow[t]{2}{*}{ Religious belief } & Yes & $60.45 \pm 10.89$ & \multirow[t]{2}{*}{2.991} & \multirow[t]{2}{*}{0.003} \\
\hline & No & $57.11 \pm 10.75$ & & \\
\hline \multirow[t]{2}{*}{ Occupational status } & $\begin{array}{l}\text { College } \\
\text { student }\end{array}$ & $57.04 \pm 10.357$ & \multirow[t]{2}{*}{-2.920} & \multirow[t]{2}{*}{0.004} \\
\hline & Social worker & $60.28 \pm 11.34$ & & \\
\hline \multirow{2}{*}{$\begin{array}{l}\text { Experience of caring for dying } \\
\text { patients/relatives }\end{array}$} & Yes & $61.76 \pm 9.57$ & \multirow[t]{2}{*}{4.012} & \multirow[t]{2}{*}{0.000} \\
\hline & No & $57.03 \pm 11.18$ & & \\
\hline \multirow[t]{2}{*}{ Exposed to knowledge about palliative care } & Yes & $61.99 \pm 10.62$ & \multirow[t]{2}{*}{4.927} & \multirow[t]{2}{*}{0.000} \\
\hline & No & $56.47 \pm 10.59$ & & \\
\hline \multirow[t]{2}{*}{ Received training on palliative care } & Yes & $64.67 \pm 10.16$ & \multirow[t]{2}{*}{4.801} & \multirow[t]{2}{*}{0.000} \\
\hline & No & $57.41 \pm 10.70$ & & \\
\hline
\end{tabular}

Table 5 Results of multiple linear regression analysis 


\begin{tabular}{|c|c|c|c|c|c|c|c|}
\hline \multirow[t]{2}{*}{ Model } & \multicolumn{2}{|c|}{$\begin{array}{l}\text { Unstandardized } \\
\text { Coefficients }\end{array}$} & \multirow{2}{*}{$\begin{array}{l}\text { Standardized } \\
\text { Coefficients } \\
\text { Beta }\end{array}$} & \multirow[t]{2}{*}{$\mathrm{t}$} & \multirow[t]{2}{*}{ Sig. } & \multicolumn{2}{|c|}{$\begin{array}{l}95.0 \% \\
\text { Confidence } \\
\text { Interval for B }\end{array}$} \\
\hline & B & $\begin{array}{l}\text { Std. } \\
\text { Error }\end{array}$ & & & & $\begin{array}{l}\text { Lower } \\
\text { Bound }\end{array}$ & $\begin{array}{l}\text { Upper } \\
\text { Bound }\end{array}$ \\
\hline Constant & 71.611 & 7.151 & & 10.014 & .000 & 57.549 & 85.672 \\
\hline Sex & 1.383 & 1.305 & .053 & 1.060 & .290 & -1.182 & 3.949 \\
\hline Age & .047 & .092 & .055 & .509 & .611 & -.135 & .229 \\
\hline Education background & .676 & 1.111 & .033 & .609 & .543 & -1.508 & 2.860 \\
\hline Marital status & 1.224 & 1.307 & .067 & .936 & .350 & -1.347 & 3.795 \\
\hline Religious belief & -.797 & 1.587 & -.036 & -.502 & .616 & -3.916 & 2.323 \\
\hline Occupational status & -.631 & 2.011 & -.029 & -.314 & .754 & -4.584 & 3.322 \\
\hline $\begin{array}{l}\text { Experience of caring for } \\
\text { dying patients/relatives }\end{array}$ & -3.274 & 1.198 & -.139 & -2.734 & .007 & -5.629 & -.919 \\
\hline $\begin{array}{l}\text { Exposed to knowledge } \\
\text { about palliative care }\end{array}$ & -2.742 & 1.276 & -.121 & -2.149 & .032 & -5.251 & -.233 \\
\hline $\begin{array}{l}\text { Received training on } \\
\text { palliative care }\end{array}$ & -4.188 & 1.698 & -.137 & -2.466 & .014 & -7.526 & -.849 \\
\hline
\end{tabular}

\section{Discussion}

\section{Volunteers' spiritual care competence}

This study found that volunteers' mean scores on spiritual care competence were not high and the overall competence needs to be improved. As a social cause, voluntary service embodies the spirit of mutual assistance, cooperation, dedication and great love, which promotes social civilization. Volunteers are an integral resource in palliative care. They play an essential role in improving the quality of the patients' life and positively affecting their families' health, whether physical, psychological or spiritual. They can provide various services, including social support, emotional support, informational support, practical support, spiritual support, respite support, physical support and bereavement support[26]. In addition, volunteer services relieve the pressure on medical stuff. It was estimated that there were around 1029 palliative care volunteers in China[27]. At present, the development of palliative care volunteers is in its infancy. The current level of volunteers' spiritual care is not high, which may be related to the the lack of knowledge and resources. The two items that scored lowest was knowledge of death and palliative care, and spiritual care resources. In addition, spiritual care began relatively late in China. The importance of spirituality has been raised at the national level, but relevant policies are lacking. There is a lack of a unified concept of spirituality[3]. And studies on the spiritual care of the dying in China have not been undertaken widely, with most of researches mainly focusing on medical care. Hospital and nursing 
institutions are relatively more involved in spiritual care. According to the research by Kichenadasse[28], most of the medical staff had been exposed to patients' spiritual need, but only $45 \%$ reported that they could satisfy their need. There is a lack of unified education content and curriculum in China. And the planning and supervision standards for spiritual care are still blank. Although volunteers have a passion for palliative care, they do not have a good command of professional knowledge and understand the concept of spiritual care. Thus, there remains an urgent need to clarify the definition of spirituality and develop systematic curriculum and training programs with a view to improving the volunteers' spiritual care competence.

The spiritual care score of social volunteers is significantly higher than that of college students, which was consistent with the result of this study that age, marital status, religious beliefs were the influencing factors of spiritual care competence. Social volunteers are relatively older and have richer experience on caring and communication. And they are inclined to have a deeper understanding of life. Moreover, $80 \%$ of the social volunteers were religious, which could partly explains the results. Fu[29] found that religion could be regarded as a spiritual resource. The religious context can be introduced into palliative care by variable spiritual care strategies, so as to provide spiritual fulcrum for the dying and ease their sense of vulnerability. Religious people usually hold a known belief about death, which helps people eliminate the fear of "unknown" death[30]. Therefore, it is important to pay attention to the value of social volunteers and strengthen the publicity of palliative care in diverse ways, hoping to attract and recruit more volunteers.

\section{Factors affecting volunteers' spiritual care competence}

The results of univariate analysis showed that age, education background, marital status, religious belief are the influencing factors of volunteers' spiritual care competence. To be specific, an older age, a higher education background, an marital status of being divorced or widowed, being religious indicating a higher level of spiritual care competence. The result of multiple linear regression analysis showed that relative practical experience, education and training are significantly associated with spiritual care competence. Taking care of patients at the end of life is also a process of self-learning and growth. Jiao[31] investigated 80 nurses and found that after systematic spiritual care training, nurses' spiritual health and spiritual care awareness had been significantly improved. Being exposed to spiritual care courses or training will largely improve clinical nurses' understanding of spiritual care, implementation methods and evaluation of effect. Volunteers who have been exposed to palliative care knowledge and received education and training have a better understanding of the concept and significance of palliative care. It can help them have a correct view of life and death, eliminate the fear of death, treat dying patients more calmly and give them better spiritual care service. Spiritual care education and training also strengthen caregivers' sense of responsibility to provide spiritual care, so as to enhance their spiritual care competence. Zhang[32] found that after systematic training of spiritual care, the cognition, competence and attitude towards palliative care were significantly improved. Spiritual care cognition is positively correlated with spiritual care competence[33]. The content and method of spiritual care are the most urgent contents for volunteers to be trained[34]. It is necessary to focus on the education of spiritual care 
cognition and develop a training and evaluation system, so as to improve volunteers' spiritual care competence.

There are abundant spiritual resources in Chinese native culture, such as the harmonious thought of the unity of man and nature, Confucius' philosophy of life, Zhuangzi's inner sanctity realm and meditation. Combined with Chinese and western philosophical concepts, a set of theoretical knowledge of spiritual care suitable for Chinese people can be developed, which can provide theoretical guidance for the development of spiritual care training system. In 2007, Hunan Cancer Hospital launched the first clinical spiritual care program in Mainland China. 26 volunteers, mainly clinical nurses, became the first batch of members through registration, expert recommendation and interviews. In 2009, 24 clinical spiritual care teachers graduated from Hunan Cancer Hospital[35]. At the same time, the international and Taiwan regions have experience in spiritual care training. For example, Chang Gung Hospital arranges spiritual nurses for dying patients to provides death education and spiritual care, so as to improve the quality of their life[36]. Shanghai has also begun to explore spiritual care training for palliative care staff through introduction of teachers from Taiwan. In the context of the extensive implementation of the pilot reform of palliative care in China, it is recommended to develop a variety of forms such as classroom education and continuing training to strengthen the publicity and education of palliative care and spiritual care. On the one hand, the faculty of medical colleges should be used to provide a range of life education and palliative care courses for students. On the other hand, spiritual care training teachers and curriculum systems are supposed be developed to carry out the continue education program for palliative care services and improve the spiritual care competence, so as to systematically improve the quality of palliative care, which will improve the value and the meaning of survival of dying patients and realize physical, spiritual and social peace.

\section{The relationship between attitude towards palliative care and spiritual care competence among volunteers}

The study showed that attitude towards palliative care was positively correlated with spiritual care competence $(p<0.001)$, indicating that volunteers who held a positive attitude towards palliative care had a higher level of spiritual care competence. The reason for this relationship may be that volunteers holding a positive attitudes towards palliative care are more passionate and have more interest in caring for the dying, so they take the initiative to learn relative knowledge and can perceive patients' spiritual need easier. In addition, volunteers holding a positive attitudes towards palliative care may have a positive attitude towards death, which help them understand the spiritual need of patients, convey a positive view of life and death in the process of palliative care[3]. On the contrary, volunteers holding a relatively negative attitudes towards palliative care may be not actively exposed to knowledge about palliative care and spiritual care, and difficult to perceive patients' spiritual need. At the same time, they may not hold a positive attitude towards death even fear of death, and may be unable to provide spiritual care effectively. Consequently, it is necessary to attach importance to volunteers' attitude towards palliative care. Selecting standards and training system are supposed to developed to improved the volunteers' spiritual care competence. 


\section{Conclusion}

The finding of this study showed that volunteers' spiritual care competence level was not high. There was a positive correlation between attitude towards palliative care and spiritual care competence among volunteers. Education and training programs are supposed to taken into account to improve the attitude towards palliative care and spiritual care competence among volunteers.

\section{Limitations}

On the one hand, although the research was conducted in typical organizations in Shanghai, the finding of the research cannot be generalized to China. On the other hand, due to the uneven distribution of samples in terms of participants characteristics, the results of multiple linear regression are not sufficient to detect all the influencing factors. More participants are needed to be investigated to assess the spiritual care competence among volunteers in China.

\section{Declarations}

\section{Acknowledgements}

We thank all the volunteers participating in our study.

\section{Authors' contributions}

WJR: Study design, data analysis, manuscript writing. XYF and LTT: Study design, data collection, data analysis. JX, SZQ and HJ: study supervision. LXY and JLM: data collection, revision, administration. All authors approved the final manuscript.

\section{Funding}

This work was supported by the Humanities and Social Science Research Planning Fund of the Ministry of Education (No.20YJAZH045); the Shanghai Natural Science Foundation; the Shanghai Municipal Philosophy and Social Science Planning Project (No.2019BGL032); Shanghai University of Chinese Medicine Scientific Research Project (No.19GJ101).

\section{Availability of data and materials}

The datasets generated and analyzed during the current study are not publicly available due to protecting the privacy of participants but are available from the corresponding author on reasonable request.

\section{Ethics approval and consent to participate}

The design of the study and participants' selection were approved by the ethical review committee of Ninth People's Hospital Affiliated to Medical School of Shanghai Jiaotong University (no. SH9H-2021T11-1). All methods used in this study were carried out in accordance with the Declaration of Helsinki and 
relevant guidelines and regulations. The respondents were told in advance about the anonymous investigation and informed consent was obtained.

\section{Consent for publication}

Not applicable.

\section{Competing interests}

The authors declare that they have no competing interests.

\section{References}

1. Assessing the development of palliative care worldwide: a set of actionable indicators. Geneva: World Health Organization; 2021.

2. Gielen J, Bhatnagar S, Chaturvedi SK: Prevalence and Nature of Spiritual Distress Among Palliative Care Patients in India. Journal of Religion and Health 2017, 56(2):530-544.

3. Li L, Lv J, Zhang L, Song Y, Zhou Y, Liu J: Association between attitude towards death and spiritual care competence of Chinese oncology nurses: a cross-sectional study. BMC PALLIAT CARE 2021, 20(1):150.

4. Chung LY, Wong FK, Chan MF: Relationship of nurses' spirituality to their understanding and practice of spiritual care. J ADV NURS 2007, 58(2):158-170.

5. Chang Guangcai, The spiritual care and social workers' intervention of the pension institutions, 2013, Jilin University.

6. DING Yanming, HUANG Ziye, WANG Yi, ZHAO Lingwei, LIU Fei, WANG Yingxin. The development status of hospice care volunteers service: a review[J].Chinese Nursing Management,2021,21(07):984987.

7. Wang Mengmeng, XU Tianmeng, YUE Peng. The Relevant Policies, Challenges and Suggestions of Palliative Care in China. Medicine \& Philosophy, 2020. 41(14):19-22.

8. Pesut B, Hooper B, Lehbauer S, Dalhuisen M: Promoting Volunteer Capacity in Hospice Palliative Care. American Journal of Hospice and Palliative Medicine ${ }^{\circledR}$ 2014, 31(1):69-78.

9. Goossensen MA, Somsen J, Scott R, Pelltari L: Defining volunteering in hospice and palliative care in Europe: an EAPC White Paper. European journal of palliative care 2016, 4(4):184-191.

10. Candy B, France R, Low J, Sampson L: Does involving volunteers in the provision of palliative care make a difference to patient and family wellbeing? A systematic review of quantitative and qualitative evidence. INT J NURS STUD 2015, 52(3).

11. Claxton-Oldfield S: Hospice palliative care volunteers: The benefits for patients, family caregivers, and the volunteers. Palliative and Supportive Care 2015, 13(3):809-813.

12. Vanderstichelen S, Cohen J, Van Wesemael Y, Deliens L, Chambaere K: The liminal space palliative care volunteers occupy and their roles within it: a qualitative study. BMJ Support Palliat Care 2020, 
10(3):e28.

13. Morris SM, Payne S, Ockenden N, Hill M: Hospice volunteers: bridging the gap to the community? Health Soc Care Community 2017, 25(6):1704-1713.

14. Burbeck R, Low J, Sampson EL, Bravery R, Hill M, Morris S, Ockenden N, Payne S, Candy B: Volunteers in specialist palliative care: a survey of adult services in the United Kingdom. J PALLIAT MED 2014, 17(5):568-574.

15. Fast J, Keating N, Otfinowski P, Derksen L: Characteristics of family/friend care networks of frail seniors. CAN J AGING 2004, 23(1):5-19.

16. Yeun YR: A Study on the Motivations of Korean Hospice Volunteers. Indian J Palliat Care 2020, 26(1):24-27.

17. Norman G, Monteiro S, Salama S: Sample size calculations: should the emperor's clothes be off the peg or made to measure? BMJ 2012, 345(aug23 1):e5278.

18. van Leeuwen $R$, Tiesinga LJ, Middel B, Post $D$, Jochemsen $H$ : The validity and reliability of an instrument to assess nursing competencies in spiritual care. J CLIN NURS 2009, 18(20):2857-2869.

19. QI Mengying, Yan Jing, Mao Ping, Huang Hui, Tian Keping, Zhang Cuijiao, Sheng Wei, YI Qifeng. The current status of spiritual care ability of nursing interns and improvement countermeasures[J]. Chinese Nursing Management, 2019, 19(04): 563-568.

20. Wei Di, Liu Xiangyu, Chen Yongyi, Zhang Min, Mao Ting, Fu Yulu. Reliability and validity of Chinese version of Spiritual Care Competence Scale[J]. Chinese Nursing Management, 2017, 17(12): 16101615.

21. YAN Yijun, BIAN Leisi, ZHANG Wenting, NI Xiushi. Spiritual Care Research in Community Hospice Care Ward Application. China Health Industry, 2016. 13(01):195-198.

22. Chen Binghua, Qiu Zhongfeng, Fan Lanxin, Zhao Ran, Wu Senqi. Identifying Spiritual Care Competencies for Providers in Hospice Palliative Care from a Christian Perspective, [J]. Taiwan Journal of Hospice Palliative Care, 2016, 21(2). 4

23. Chen Binghua, Qiu Zhongfeng, Zhang Guofeng, Zhao Ran, Fan Lanxin, Zhu Meijuan. Development and Psychometric Properties of the Spiritual Care Competency Scale, [J]. Chinese Journal of Psychology, 2017, 30(2): 141-167

24. Frommelt $\mathrm{KH}$ : Attitudes toward care of the terminally ill: an educational intervention. Am J Hosp Palliat Care 2003, 20(1):13-22.

25. Liu WJ, Hu WY, Chiu YF, Chiu TY, Lue BH, Chen CY, Wakai S: Factors that influence physicians in providing palliative care in rural communities in Taiwan. SUPPORT CARE CANCER 2005, 13(10):781789.

26. Claxton-Oldfield S, Hastings E, Claxton-Oldfield J: Nurses' perceptions of hospice palliative care volunteers. Am J Hosp Palliat Care 2008, 25(3):169-178.

27. National Health Commission of the People's Republic of China: letter on the reply to proposal no. 4616 (medical and sports no. 674) of the third session of the 13th national committee of the chinese 
people's political consultative conference; 2021.

28. Kichenadasse G, Sweet L, Harrington A, Ullah S: The current practice, preparedness and educational preparation of oncology professionals to provide spiritual care. Asia Pac J Clin Oncol 2017, 13(5):e506-e514.

29. Fu Lingqing. Discussion on the 2D Structure of the Value in Hospice Service Action System. [D]. Shenyang Normal University, 2016.

30. Sun Panpan, Deng Meijuan, Jiang Zhe, .Related Factors of Spiritual Needs of Cancer patients. [J]. Medicine and Philosophy, 2019, 40(02): 43-48.

31. Jiao Miaorui, Hu Yanli,Zhang Lin, Fang Fang, Wang Yizhuo, Mi Yanzhi, Li Xiujie. Effects of spiritual care training on improving nurses' spiritual well-being and perceptions of spiritual care[J]. Chinese Journal of Modern Nursing, 2020(04): 435-441.

32. Zhang Juan. The construction of the training program of the nurses' spiritual care ability in oncology department and effect comparison of different training patterns[D]. Nanchang University, 2020.

33. Shi Yan, Zhao Yiting, Hu Yanli, Zhou Jingjing, Xu Xiaoxia. Correlation between spiritual care competence and spiritual care-giving in oncology nurses[J]. Medicine and Philosophy, 2020, 41(07): 55-58.

34. JING Limei, LI Tiantian, SHU Zhiqun, TENG Xiaohan, HUI Jue, WANG Yiting, JUE Xing. Study on the volunteers' Knowledge, Attitude, Behavior and Training Needs of Hospice Care[J]. Medicine \& Philosophy,2020,41(21):30-34.

35. Shen Boyong, Chen Yongyi, Tang Xinhui. Managerment and practice of clinical spiritual care for patients with cancer[J]. Chinese Nursing Management, 2012, 12(5): 65-66.

36. Yu Lejing. An introduction to humanistic care in Chang Gung hospital of Taiwan[J]. Journal of Nursing Science, 2012, 27(13): 21. 